\title{
Uncarboxylated osteocalcin promotes osteogenesis and inhibits adipogenesis of mouse bone marrow-derived mesenchymal stem cells via the PKA-AMPK-SIRT1 axis
}

\author{
LE GAO, FANG-ZI GONG, LU-YAO MA and JIAN-HONG YANG \\ Savaid Medical School, University of Chinese Academy of Sciences, Beijing 100049, P.R. China
}

Received September 18, 2020; Accepted April 27, 2021

DOI: $10.3892 /$ etm.2021.10312

\begin{abstract}
Osteoporosis is a bone disease characterized by reduced bone density, thin cortical bone and large gaps in the bone's honeycomb structure, which increases the risk of bone fragility. Uncarboxylated osteocalcin (unOC), a vitamin K-dependent bone protein, is known to regulate carbohydrate and energy metabolism. A previous study demonstrated that unOC promotes the differentiation of mouse bone marrow-derived mesenchymal stem cells (BMSCs) into osteoblasts, but inhibits their differentiation into adipocytes. However, the underlying mechanism remains unknown. The present study showed that unOC regulated the differentiation potential of BMSCs via protein kinase A (PKA)/AMP-activated protein kinase (AMPK)/sirtuin 1 (SIRT1) signaling. SIRT1, a member of the sirtuin family with deacetylation functions, was upregulated by unOC in BMSCs. Transfection analyses with SIRT1 small interfering RNA indicated that the unOC-induced differentiation shift in BMSCs required SIRT1. Examination of SIRT1 downstream targets revealed that unOC regulated the acetylation levels
\end{abstract}

Correspondence to: Dr Jian-Hong Yang, Savaid Medical School, University of Chinese Academy of Sciences, 380 Huaibei Village, Beijing 100049, P.R. China

E-mail: yangjh@ucas.edu.cn

Abbreviations: unOC, uncarboxylated osteocalcin; BMSCs, bone marrow-derived mesenchymal stem cells; sFRP, secreted frizzled-related protein; ALP, alkaline phosphatase; SIRT1, sirtuin 1; RT-qPCR, reverse transcription-quantitative PCR; Osx, osterix; RUNX, runt-related transcription factor; Fabp4, fatty acid-binding protein 4; PPAR $\gamma$, peroxisome proliferator-activated receptor g; PKA, protein kinase A; AMPK, AMP-activated protein kinase; NAD, nicotinamide adenine dinucleotide; LKB1, liver kinase B1; $\alpha$-MEM, $\alpha$-minimal essential medium; FAS, fatty acid synthase; siRNA, small interfering RNA; ODI; osteogenic differentiation inducers; TBST; Tris-buffered saline with Tween 20; C/EBP $\alpha$, CCAAT-enhancer-binding protein a; $\mathrm{NG}$; normal group; $\mathrm{NC}$, negative control

Key words: uncarboxylated osteocalcin, bone marrow-derived mesenchymal stem cells, osteogenic differentiation, sirtuin 1, signaling pathway of runt-related transcription factor (RUNX) 2 and peroxisome proliferator-activated receptor $\gamma$ (PPAR $\gamma$ ). Therefore, unOC inhibited adipogenic differentiation by PPAR $\gamma$ acetylation and promoted osteogenic differentiation by RUNX2 deacetylation. Moreover, phosphorylated PKA and AMPK protein levels increased after unOC treatment, which led to the upregulation of SIRT1. Western blot analysis with PKA and AMPK inhibitors indicated that the PKA-AMPK signaling pathway functioned upstream of SIRT1 and positively regulated SIRT1 expression. These findings led us to propose a model in which unOC regulated BMSC osteogenic differentiation through the PKA-AMPK-SIRT1 axis, giving evidence towards the therapeutic potential of unOC in osteoporosis treatment.

\section{Introduction}

Osteoporosis is a bone disease characterized by decreased bone mass, bone microstructure degeneration or destruction and an increased fracture rate (1). Bone marrow-derived mesenchymal stem cells (BMSCs) can differentiate into a variety of cells, such as adipocytes, chondrocytes and nerve cells. However, their differentiation into cell types other than osteoblasts may lead to a decrease in the number of bone cells, eventually resulting in osteoporosis (2). Previous studies have shown that exogenous mesenchymal stem cell (MSC) transplantation can restore the impaired function of BMSCs, thereby promoting osteoblast formation and increasing bone regeneration $(3,4)$. Mo et al $(5)$ also reported that a compound extracted from Phyllanthus amarus promotes the osteogenic differentiation of BMSCs and increases bone mass by activating the Wnt/ $\beta$-catenin signaling pathway. In addition, Luo et al (6) found that runt-related transcription factor (RUNX) 1 regulates the osteogenic differentiation of BMSCs by inhibiting adipogenesis-related pathways. Therefore, BMSCs are beneficial for osteoblast regeneration and bone remodeling, and are expected to be utilized for the treatment of bone-related diseases such as osteoporosis and osteoarthritis (7).

Factors that affect the differentiation of BMSCs include physical (cell shape and external mechanical forces), chemical (dexamethasone and insulin are required for adipogenic differentiation), biological (mineral deposition and cell proliferation) and age (senescence) $(8,9)$. Osteocalcin is a vitamin K-dependent bone protein that is synthesized in the human body by osteoblasts (10). In particular, $\gamma$-glutamate 
carboxylase can catalyze the carboxylation of three glutamates at positions 17, 21 and 24 in the molecular structure of osteocalcin (11). According to whether these three sites are fully carboxylated, osteocalcin can be divided into two subtypes: $\gamma$-Carboxyl osteocalcin and incomplete carboxylated/uncarboxylated osteocalcin (unOC) (11). Previous studies have shown that osteocalcin-knockout in mice can affect bone mineralization $(12,13)$. Therefore, osteocalcin is hypothesized to affect osteoblast and osteoclast activity to regulate mineralization $(14,15)$. A previous study indicated that unOC can promote the differentiation of BMSCs into osteoblasts (16). However, further study is required to identify the specific mechanism by which unOC regulates the osteogenic differentiation of MSCs.

Studies have shown that sirtuin 1 (SIRT1) is associated with the differentiation of MSCs $(17,18)$. SIRT1 is a nicotinamide adenine dinucleotide $\left(\mathrm{NAD}^{+}\right)$-dependent lysine deacetylase. It activates the Wnt signaling pathway and promotes MSC osteogenic differentiation by the deacetylation of secreted frizzled-related protein 1 (sFRP1), sFRP2 and disheveled-binding antagonist of $\beta$ catenin $1(19,20)$. SIRT1 positively regulates RUNX2, a key transcription factor associated with osteoblasts, to activate the transcription of BMSC osteogenic differentiation (21). SIRT1 can also deacetylate peroxisome proliferator-activated receptor $\gamma$ (PPAR $\gamma)$, inhibiting PPAR $\gamma$ activity and attenuating lipogenesis to enhance osteogenic differentiation (22). Therefore, it was hypothesized that unOC can promote the differentiation of BMSCs through SIRT1, thereby promoting osteogenic formation.

5 'AMP-activated protein kinase (AMPK) is a protein kinase closely associated with glucose metabolism (23). Increasing evidence suggests that SIRT1 and AMPK can interact to regulate the osteogenic and adipogenic differentiation of MSCs (24). AMPK can increase SIRT1 activity by promoting $\mathrm{NAD}^{+}$biosynthesis, where SIRT1 can also upregulate AMPK activity through the liver kinase B1 (LKB1)-AMPK axis (25). A previous study reported that protein kinase A (PKA) regulates SIRT1 expression by activating serine/threonine kinase LKB1 (26). Based on these studies, it was hypothesized that unOC regulated $\mathrm{BMSC}$ differentiation into osteoblasts via the PKA-AMPK-SIRT1 axis.

The present study aimed to further explore the mechanism and the signaling pathways associated with the promotion of BMSC osteogenic differentiation by unOC and to uncover novel avenues for the treatment of osteoporosis.

\section{Materials and methods}

Preparation of $u n O C$. unOC was prepared as previously described by Liu and Yang (16) with slight modifications. The method used to lyse the bacteria in the present study was to freeze the bacteria at $-80^{\circ} \mathrm{C}$ before using an ultrasonic cell disruptor. In brief, the plasmid pet30a (cat no. JX210976.1 GI:392880915; Biovector Science Lab, Inc.; http://www. biovector.net/product/1040481.html) containing the mouse unOC recombinant gene was previously constructed in the laboratory (27). It was made by amplifying the mouse osteocalcin gene (accession no. NM_007541) sequences by PCR based on NCBI database (The source of the template: Mouse bone tissue), cloning into the pet-30a vector to obtain the pet-30a-OC recombinant plasmid. It was introduced into Escherichia coli, and bacteria populations containing the plasmid vector with a resistance gene were selected with kanamycin antibiotic (1:1,000; cat. no. K1010; Beijing Lablead Biotechnology Co., Ltd.). The selected populations were cultured in liquid phase to the $\log$ phase at $37^{\circ} \mathrm{C}$ for $8 \mathrm{~h}$ and induced to express recombinant osteocalcin with $1 \mathrm{mM}$ isopropyl $\beta$-d-1-thiogalactopyranoside at $28.5^{\circ} \mathrm{C}$ for $3 \mathrm{~h}$. Protein (mouse unOC with a six-histidine tag) extraction and purification processes were performed in accordance with the previous description (28). The obtained osteocalcin was isolated, purified by binding to a recombinant protein in a $\mathrm{Ni}$ Sepharose $^{\mathrm{TM}} 6$ Fast Flow column (cat. no. 17531801; Cytiva), and eluted with $150 \mathrm{mM}$ of imidazole (cat. no. II0070; Beijing Solarbio Science \& Technology Co., Ltd.). The purified protein was dialyzed and concentrated. The molecular weight of the protein was determined using $10 \%$ SDS-PAGE (the amount of protein loaded per lane: $20 \mu \mathrm{g}$ ) and Coomassie blue staining (Coomassie Blue Fast Staining Solution; cat. no. P0017; Beyotime Institute of Biotechnology) was used. Experimental conditions for Coomassie staining: $50 \mathrm{ml}$ deionized water was added to the protein gel and heated at $100^{\circ} \mathrm{C}$ for $3 \mathrm{~min}$, before being shaken on a horizontal shaker at $37^{\circ} \mathrm{C}$ for $5 \mathrm{~min}$. the gels were then incubated in $\sim 20 \mathrm{ml}$ Coomassie Blue Fast Staining Solution at $100^{\circ} \mathrm{C}$ for $3 \mathrm{~min}$ and incubated on a shaker at a temperature of $37^{\circ} \mathrm{C}$ to decolorize. Protein bands were observed at room temperature after $2 \mathrm{~h}$. Western blot analysis was used for protein detection.

Cell culture and differentiation. In total, 12 4-week-old male C57BL/6 mice (certificate no. SCXK 2016-0006) were purchased from Charles River Laboratories, Inc. During the research process, all animal experiments were conducted in accordance with the standards in University of Chinese Academy of Sciences Institutional Committee for the Use and Care of Animals. The mice (weight range, 16-18 g) were used for each experiment. Housing conditions are $25^{\circ} \mathrm{C}$, relative air humidity: $50-60 \%$. Mice had free access to food and water and were on a 12-h light/dark cycle. All experimental protocols for the present study were approved by The Institutional Animal Care and Use Committee of the University of Chinese Academy of Sciences (Beijing, China). Isolation and culture of mouse BMSCs were performed as described previously by Cai et al (29). Briefly, mice were sacrificed through cervical dislocation, the tibia and femur were separated and the surrounding muscle tissue was removed. The removed bone tissue was placed in PBS with $100 \mathrm{U} / \mathrm{ml}$ penicillin and $100 \mathrm{mg} / \mathrm{l}$ streptomycin (the double antibody, and both ends of the tibia and femur were removed. Bone marrow was flushed out using serum-free $\alpha$-Minimal Essential Medium ( $\alpha$-MEM; Gibco; Thermo Fisher Scientific, Inc.). The collected media were centrifuged at $278 \mathrm{x} \mathrm{g}$ for $10 \mathrm{~min}$ at $37^{\circ} \mathrm{C}$, resuspended in $\alpha$-MEM supplemented with 10\% FBS (cat. no. S601P-500; Sera Pro), $100 \mathrm{U} / \mathrm{ml}$ penicillin and $100 \mathrm{mg} / 1$ streptomycin. Cells were incubated at $37^{\circ} \mathrm{C}$ in $5 \% \mathrm{CO}_{2}$ for $72 \mathrm{~h}$, and half of the growing medium was replaced every $12 \mathrm{~h}$. Fresh medium was added and was replaced every 2 days thereafter. BMSCs were then expanded for a maximum of four passages, trypsinized and seeded at a density of $\sim 1 \times 10^{6}$ cells per well in six-well 
plates, followed by adipogenic or osteogenic differentiation analysis.

To induce BMSCs to differentiate into osteoblasts, cells were cultured in $\alpha$-MEM medium and osteogenic differentiation inducer (ODI) containing $50 \mathrm{mg} / \mathrm{ml} \mathrm{L}$-ascorbic acid (cat. no. A4544-25G), $10 \mathrm{mM} \beta$-glyceryl phosphate (cat. no. 50020) and $100 \mathrm{nM}$ dexamethasone (cat. no. D1756) (all Sigma-Aldrich; Merck KGaA) was used. Control cells were cultured in $\alpha$-MEM medium containing $10 \% \mathrm{FBS}$ and $1 \%$ penicillin/streptomycin only. unOC-treated cells were cultured in osteogenic differentiation medium containing $3 \mathrm{ng} / \mathrm{ml}$ of unOC. BMSCs were divided into four groups: Normal control group (NG), unOC-treated group, $\mathrm{NG}+\mathrm{ODI}$ group and unOC + ODI group. All cells were incubated at $37^{\circ} \mathrm{C}$ and $5 \% \mathrm{CO}_{2}$ for 3 weeks.

The third-generation BMSCs were used to detect the adipogenic differentiation potential of the cells. The composition of the adipogenic differentiation inducer (ADI) was as follows: $1 \mathrm{mmol} / 1$ Dexamethasone, $0.5 \mathrm{mmol} / 1$ 3-isobutyl-1-methylxanthine, $10 \mathrm{mg} / \mathrm{l}$ insulin and $0.2 \mathrm{mmol} / \mathrm{l}$ indomethacin (all Sigma-Aldrich; Merck KGaA). The BMSCs with ADI were placed in a $\mathrm{CO}_{2}$ constant-temperature incubator, the cells were cultured at $37^{\circ} \mathrm{C}$ and $5 \% \mathrm{CO}_{2}$ for 3 weeks, and the medium was changed every day.

Alizarin red staining and oil red O staining. After the BMSCs were cultured under different osteoblast differentiation conditions for 3 weeks, cells were washed twice with PBS, fixed with $10 \%$ neutral formaldehyde at $37^{\circ} \mathrm{C}$ for $30 \mathrm{~min}$, and washed twice with PBS before subjected to staining with Alizarin Red S (cat. no. G3281; Beijing Solarbio Science \& Technology Co., Ltd.) at $37^{\circ} \mathrm{C}$ for $30 \mathrm{~min}$. Optical microscope (Leica Microsystems $\mathrm{GmbH}$ ) was used to capture high-resolution images of the stained calcium nodules (light, x40 magnification). In order to quantify the calcium content in each sample, Alizarin Red was eluted with $10 \%$ (wt/vol) cetylpyridinium chloride (cat. no. C9890; Beijing Solarbio Science \& Technology Co., Ltd.), and the optical density of the eluate was determined using an automatic microplate reader (BioTek China) at a wavelength of $540 \mathrm{~nm}$.

After culturing with ADI for 3 weeks, the lipid droplets in the cells were measured using Oil red O (ORO) staining. The ORO dye was prepared by slowly adding $0.1 \mathrm{~g}$ Oil red O (Sigma-Aldrich; Merck KGaA) to $100 \mathrm{ml} \mathrm{60 \%} \mathrm{isopropanol}$ while mixing the solution continuously, followed by heating for $5 \mathrm{~min}$ at $60^{\circ} \mathrm{C}$, filtering and diluting with deionized water before use (Oil red O saturated liquid: Deionized water, 3:2). The treated cells were fixed with $10 \%$ paraformaldehyde (Biosharp Life Sciences) at $37^{\circ} \mathrm{C}$ for $30 \mathrm{~min}$. The excess liquid was removed and $0.5 \%$ ORO dye solution was added for $20 \mathrm{~min}$ at $37^{\circ} \mathrm{C}$. Before microscopic examination, a small amount of $75 \%$ ethanol was used to wash out excess dye if necessary. Lipid droplet images were obtained using a high-resolution optical microscope (Leica Microsystems GmbH) (light, x40 magnification). The dye was extracted with $100 \%$ isopropanol and the absorbance was measured at $500 \mathrm{~nm}$ with an automatic microplate reader (BioTek China).

Cell transfection. Transfection was performed when mouse BMSCs were passaged to the third generation and $60-80 \%$ of the adherent cells were confluent. Small interfering RNA (siRNA) targeting SIRT1 (forward 5'-CCCUCAAGCCAU GUUUGAUTT-3' and reverse 5'-AUCAAACAUGGCUU GAGGGTT-3') and negative control (NC; forward 5'-UUC UCCGAACGUGUCACGUTT-3' and reverse 5'-ACGUGA CACGUUCGGAGAATT-3') siRNA were purchased from JTS Scientific (30). The overall transfection procedure was in accordance with the recommendations of the manufacturer. Lipofectamine ${ }^{\circledR} 3000$ (cat. no. L3000015; Invitrogen; Thermo Fisher Scientific, Inc.) was used to transfect $20 \mathrm{nM}$ of the siRNA and the NC siRNA into the cells at $37^{\circ} \mathrm{C}$. The cells were continuously transfected in medium with or without unOC until they were used for experiments. Finally, protein samples or RNA were collected for further experiments. The time interval between transfection and subsequent experiments was $48 \mathrm{~h}$.

$R N A$ preparation and reverse transcription-quantitative $(R T-q) P C R$ analysis. Total cellular RNA was extracted using $1 \mathrm{ml} \mathrm{TRIzol}{ }^{\circledR}$ reagent (Invitrogen; Thermo Fisher Scientific, Inc.) per $10-\mathrm{cm}$ plate. Total RNA was reverse transcribed into cDNA using TransScript ${ }^{\circledR}$ One-Step gDNA Removal and cDNA Synthesis SuperMix (cat. no. A T311-03; Beijing Transgen Biotech Co., Ltd.) and TransStart ${ }^{\circledR}$ Top Green qPCR SuperMix (+Dye II) for qPCR (cat. no. AQ132-24; Beijing Transgen Biotech Co., Ltd.). Full temperature protocol for RT: The product after cDNA synthesis was incubated at $42^{\circ} \mathrm{C}$ for $15 \mathrm{~min}$, and then heated at $85^{\circ} \mathrm{C}$ for $5 \mathrm{sec}$ to inactivate excess reagents. The thermocycling conditions were $95^{\circ} \mathrm{C}$ for $5 \mathrm{~min}$, then 40 cycles of $94^{\circ} \mathrm{C}$ for $30 \mathrm{sec}, 56^{\circ} \mathrm{C}$ for $30 \mathrm{sec}$ and $72^{\circ} \mathrm{C}$ for $30 \mathrm{sec}$. Gapdh served as the internal standard. The expression levels of target genes were normalized to the expression of Gapdh mRNA. The following primers were used to determine the expression levels of proteins associated with osteogenic differentiation: Fatty acid-binding protein 4 (Fabp 4 ) forward 5'-AAGTGGGAGTGGGCTTTG-3', and reverse 5'-GTCGTC TGCGGTGATTTC-3'; fatty acid synthase (Fas) forward 5'-TGCTTGCTGGCTCACAGTTAAGAG-3', and reverse 5'-TCAGGTTGGCATGGTTGACAGC-3'; osterix (Osx) forward 5'-CTAGTTCCTATGCTCCGACC-3', and reverse 5'-TCATCACATCATCATCGTG-3'; alkaline phosphatase (Alp) forward 5'-CAAAGGCTTCTTCTTGCTGGT-3', and reverse 5'-AAGGGCTTCTTGTCCGTGTC-3'; and Gapdh forward 5'-GGCATTGCTCTCAATGACAA-3', and reverse 5'-TGTGAGGGAGATGCTCAGTG-3'.

Immunoprecipitation. The cell culture medium was aspirated and washed three times with ice-cold $4^{\circ} \mathrm{C}$ PBS. Afterward, RIPA lysis buffer (cat. no. R0020; Beijing Solarbio Science \& Technology Co., Ltd.) was added to lyse the cells. Detection of protein concentration: BCA Protein Assay kit (Beyotime Institute of Biotechnology). A total of $200 \mu \mathrm{g}$ protein samples and $20 \mu \mathrm{g}$ protein A+G Agarose beads (cat. no. P2012; Beyotime Institute of Biotechnology) were used. The mixture was shaken slowly at $4^{\circ} \mathrm{C}$, then centrifuged at $1,000 \times \mathrm{g}$ for 5 min and the supernatant was collected for subsequent immunoprecipitation experiments. In total, $2 \mu \mathrm{g}$ the primary antibody, including anti-RUNX2 (cat. no. 12556; Cell Signaling Technology, Inc.), anti-PPAR $\gamma$ (cat. no. 2443; Cell Signaling Technology, Inc.), anti-acetylated-lysine (cat. no. 9441; Cell 
Signaling Technology, Inc.) was added and shaken slowly overnight at $4^{\circ} \mathrm{C}$. Afterwards, completely resuspended $40 \mu \mathrm{g}$ Protein A + G Agarose was added and the mixture was slowly shaken at $4^{\circ} \mathrm{C}$ for $3 \mathrm{~h}$. Centrifuge at $278 \mathrm{xg}$ for $5 \mathrm{~min}$ at $4^{\circ} \mathrm{C}$ for washing. After the last wash, the supernatant was removed, 5X SDS-PAGE electrophoresis loading buffer was added, and the resulting pellet was resuspended and vortexed. The sample was centrifuged to the bottom of the tube by instantaneous high-speed centrifugation. After $5 \mathrm{~min}$ incubation in a $100^{\circ} \mathrm{C}$ water bath, some or all samples were collected for western blotting.

Western blotting. BMSCs were washed three times with ice-cold PBS, and lysed with RIPA (cat. no. R0010; Beijing Solarbio Science \& Technology Co.,Ltd.) buffer. Lysate was crushed with an ultrasonic cell disruptor and the supernatant was reserved. Conditions used for cell were $300 \mathrm{~W}$ sound waves, duration of 3 min with, 3 -sec intervals at $0^{\circ} \mathrm{C}$. The protein concentrations were determined using a Beyotime BCA Protein Assay kit (Beyotime Institute of Biotechnology). Afterward, $20 \mu \mathrm{g}$ cell lysate (each electrophoresis lane) was separated using a $10 \%$ SDS-PAGE gel and transferred to a PVDF membrane. After blocking with $5 \%$ milk at $37^{\circ} \mathrm{C}$ for $2 \mathrm{~h}$, the membrane was incubated with primary antibodies $(1: 1,1000)$ at $4^{\circ} \mathrm{C}$ for $12 \mathrm{~h}$. The membrane was washed three times using Tris-buffered saline with $0.1 \%$ Tween-20 (TBST) on a shaker for $10 \mathrm{~min}$, and then incubated with secondary antibody at $37^{\circ} \mathrm{C}$ for $1 \mathrm{~h}$. After washing three times with TBST, 10 min each time, bands were detected with Immobilon Western Chemilum HRP Substrate (EMD Millipore). The band's optical density value was quantified using Image Lab Software for PC Version 6.1 (Bio-Rad Laboratories, Inc.). The protein quantity was calculated as the optical density value of the protein measured/the optical density value of an internal reference.

Antibodies used in western blot analysis included the following: Anti- $\beta$-actin (cat. no. CPA9066; Cohesion Biosciences, Ltd.), anti-SIRT1 (cat. no. 3931), anti-RUNX2 (cat. no. 12556), anti-PPAR $\gamma$ (cat. no. 2443), anti-CCAAT-enhancer-binding protein alpha (C/EBP $\alpha$; cat. no. 2295), anti-acetylated-lysine (cat. no. 9441), anti-PKA (cat. no. 4782), anti-phosphorylated (p)-PKA (cat. no. 4781), anti-AMPK (cat. no. 5831) and anti-p-AMPK (cat. no. 2535) (all Cell Signaling Technology, Inc.). The secondary antibody used was Goat anti-Rabbit IgG (H+L)-HRP (cat. no. S0101-100; Beijing Lamblide Trading Co., Ltd.) at a dilution of 1:5,000.

Signaling pathway inhibition. Cells were pretreated with or without $10 \mu \mathrm{M} \mathrm{H} 89$ (a potent inhibitor of PKA; cat. no. T6250) (31) or $10 \mu \mathrm{M}$ Dorsomorphin (an effective inhibitor of AMPK; cat. no. T1977; both TargetMol) (32) for $1 \mathrm{~h}$, then cultured for $48 \mathrm{~h}$ with or without unOC.

Statistical analysis. Data are expressed as the mean \pm standard deviation. Statistical analyses for two groups were performed using the two-tailed paired Student's t-test. Examination of more than two groups was conducted using one-way ANOVA using SPSS software (version 19.0; IBM Corp.). Bonferroni's correction method was performed as a post hoc test after one-way ANOVA. $\mathrm{P}<0.05$ was considered to indicate a statistically significant difference.

\section{Results}

ODI induces osteogenic differentiation of BMSCs. First, the osteogenic differentiation potential of BMSCs was determined. In contrast to undifferentiated BMSCs, differentiated osteoblasts accumulate a large amount of extracellular calcium deposits (mineralization). This process is accompanied by the formation of bone nodules (33). Osteoblast-mediated mineralization is therefore indicative of the formation of bone mass and can be specifically detected using Alizarin Red S $(34,35)$. Confluent fourth passage cells were cultured in medium containing ODI and control cells were cultured in the same medium without ODI. After 3 weeks, cells were stained with Alizarin Red to gauge the degree of osteogenic differentiation. The ODI-treated group was observed to have more calcium nodules compared with the control group (Fig. 1C and D). In addition, the NG + ADI group showed more lipid droplets than the NG group (Fig. 1A and B). The quantitative results were statistically significant, indicating that BMSCs had the potential for osteogenic differentiation and adipogenic differentiation (Fig. 1E and F).

unOC promotes osteogenic differentiation of BMSCs and inhibits adipogenic differentiation through SIRTI deacetylation of RUNX2 and PPAR $\gamma$

unOC promotes osteogenic differentiation of BMSCs. To determine the effect of unOC on osteogenic differentiation, the BMSCs were divided into four groups: $\mathrm{NG}$, unOC, $\mathrm{NG}+$ ODI And unOC + ODI. Alizarin Red staining was performed after 3 weeks of culture. It was found that the unOC group had more calcium nodules compared with the NG group (Fig. 2A and B). Similar results were observed in the $\mathrm{NG}+$ ODI group, indicating that unOC can function in the same manner as ODI to promote the differentiation of BMSCs into osteoblasts (Fig. 2C). In addition, the number of calcium nodules in the unOC + ODI treatment group was higher compared with that in the NG + ODI group (Fig. 2D). Quantification of Alizarin Red-positive areas indicated that significant increase in unOC and unOC + ODI groups compared with that in the NG group (Fig. 2E), suggesting that unOC can promote and facilitate the differentiation of mouse BMSCs into osteoblasts.

unOC promotes osteogenic differentiation of BMSCs and inhibits adipogenic differentiation through SIRT1. To assess whether unOC-induced osteogenic differentiation of BMSCs was mediated by SIRT1, transient transfection analysis was performed using SIRT1 siRNA and RT-qPCR analysis was used to determine that expression levels of two differentiation-related factors, ALP and OSX. Cells were divided into four groups: NG + NC, unOC Treatment + NC group, SIRT1 siRNA group and SIRT1 siRNA and unOC treatment group (unOC + SIRT1). RT-qPCR analysis showed that the expression levels of Sirt1, Alp and Osx significantly increased in the unOC + NC treatment group compared with the $\mathrm{NG}+\mathrm{NC}$ group (Fig. 3A-C). In contrast, the expression levels of Alp and $O s x$ significantly decreased in the SIRT1 siRNA transient transfected group compared with the NG + NC group. Moreover, their expression could not be recovered even when unOC was applied, suggesting that unOC promotes the 

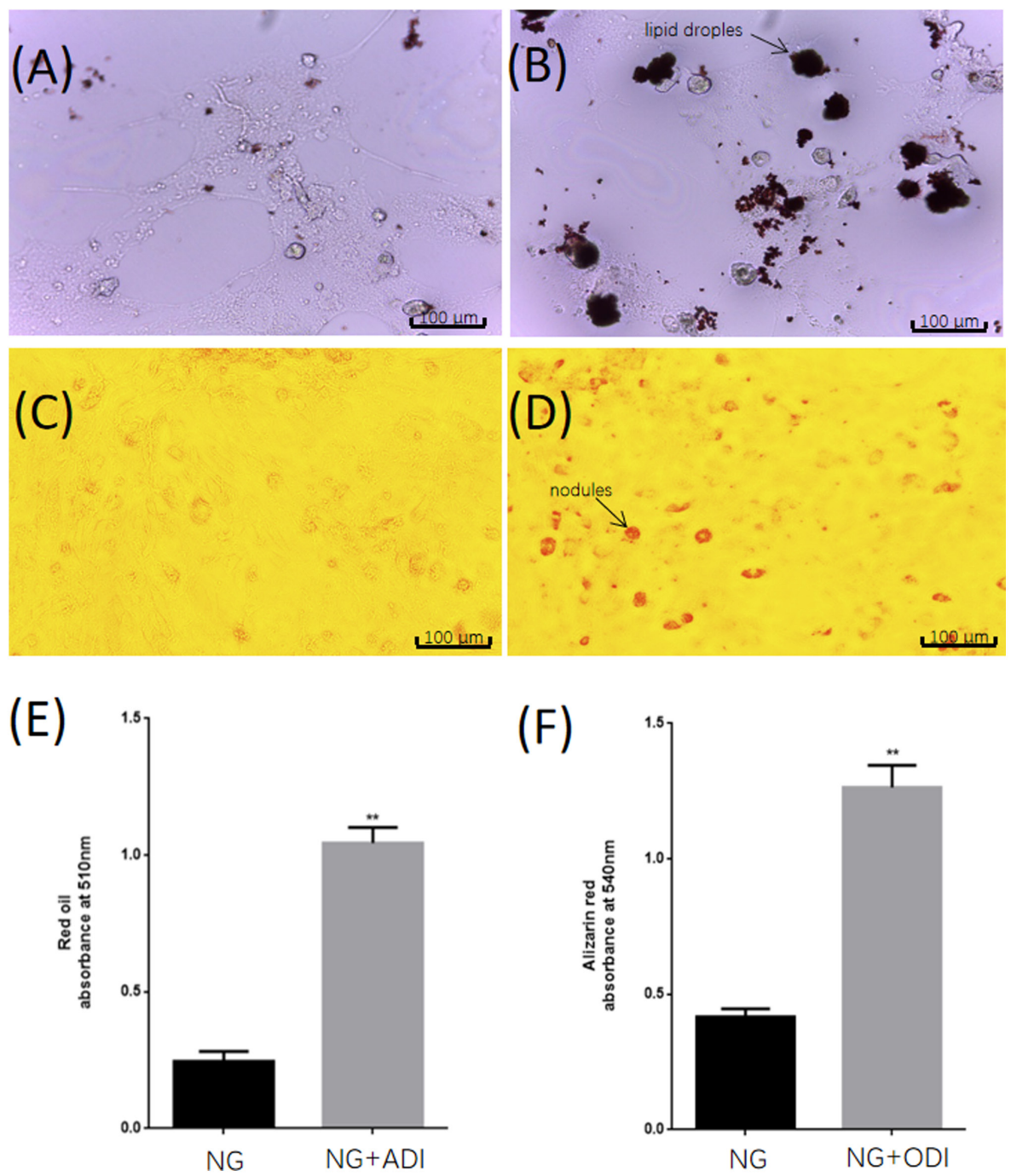

Figure 1. Induction of BMSCs into adipogenic differentiation and osteogenic differentiation. Formation of lipid droplets in the (A) NG and (B) NG + ADI groups. Calcium nodules in the (C) NG and (D) NG + ODI. (E) Quantification of NG and NG + ADI lipid droplets. (F) Quantification of calcium nodules. Experiments were repeated at least three times. Scale bar, $100 \mu \mathrm{m} .{ }^{* *} \mathrm{P}<0.01$ vs. NG. BMSCs, bone marrow-derived mesenchymal stem cells; NG, normal group; NG + ADI, adipogenic differentiation induction group; NG + ODI, osteogenic differentiation induction group.

osteogenic differentiation of mouse BMSCs through SIRT1 and that unOC cannot counteract the effects of SIRT1 siRNA.

To determine whether unOC inhibits adipogenic differentiation through SIRT1, two notable factors associated with adipogenic differentiation were examined, FAS and FABP4. It was observed that Fas and Fabp4 expression levels decreased in the unOC treatment group, indicating that unOC inhibited the adipogenesis of mouse BMSCs (Fig. 3D and E). The expression levels of Fas and Fabp4 significantly increased in the SIRT1 siRNA-transfected group compared with those in the NG + NC group. After knocking down SIRT1, this increase was not reversible even after reintroducing unOC, indicating that the inhibition of the adipogenic differentiation by unOC was mediated by SIRT1.

unOC regulates BMSC differentiation through SIRTI deacetylation of RUNX2 and PPAR $\gamma$. To determine whether the ability of unOC to regulate osteogenic differentiation was mediated through the acetylation function of SIRT1, SIRT1's downstream targets, RUNX2 and PPARr, were examined. Cells were divided into four groups: $\mathrm{NG}+\mathrm{NC}$, unOC $+\mathrm{NC}$,
SIRT1 siRNA And SIRT1 siRNA + unOC. Western blot analysis was performed in the total cell lysates for each group. It was found that unOC treatment significantly reduced the acetylation levels of PPAR $\gamma$ and RUNX2 compared with those in the NG + NC group. By contrast, their acetylation levels increased after SIRT1-knockdown (Fig. 4A, B, D and E). The acetylation states of PPAR $\gamma$ and RUNX2 have opposite effects on their activity and the PPAR $\gamma$ activity is enhanced in the acetylation state $(22,36)$. Therefore, SIRT1 can reduce the activity of PPAR $\gamma$ and inhibit adipogenic differentiation. The results of the present study suggested that unOC deacetylated PPAR $\gamma$ through SIRT1 and downregulated the activity of PPAR $\gamma$, thereby inhibiting the differentiation of BMSCs into adipocytes.

To further confirm that unOC inhibited the adipogenic differentiation of BMSCs by upregulating SIRT1, the adipogenic differentiation-related factor, $\mathrm{C} / \mathrm{EBP} \alpha$, was analyzed and its expression was examined in four groups of cells: $\mathrm{NG}+\mathrm{NC}$, unOC + NC, SIRT1 siRNA And SIRT1 siRNA + unOC. It was found that SIRT1-knockdown resulted in marked increases in the $\mathrm{C} / \mathrm{EBP} \alpha$ protein abundance (Fig. 4C) 

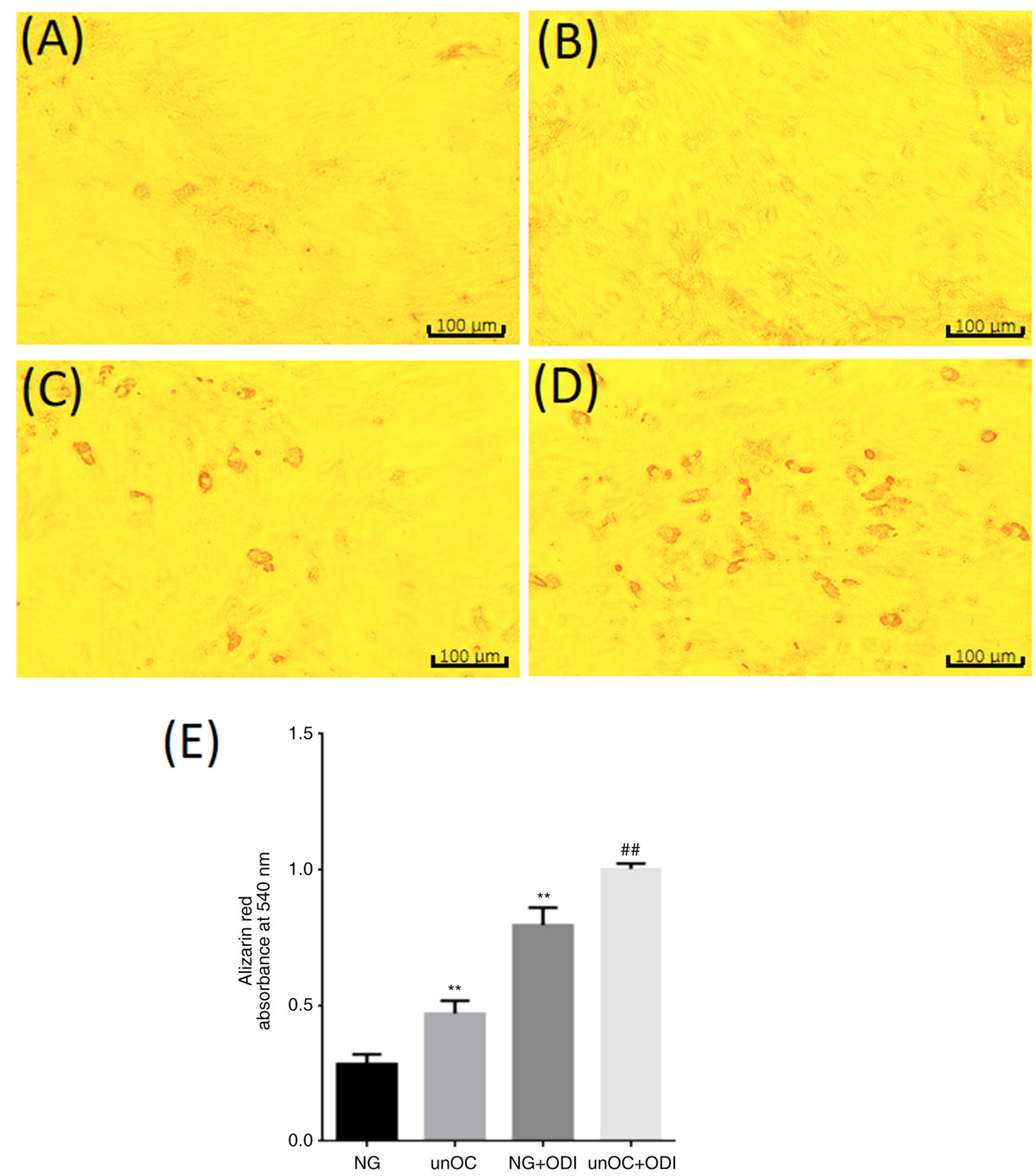

Figure 2. unOC promotes the differentiation of BMSCs into osteoblasts. Calcium nodules in the (A) NG, (B) NG + unOC, (C) NG + ODI and (D) NG + ODI + unOC groups. All cells were treated with Alizarin Red after 3 weeks of culture. (E) Quantification of Alizarin Red staining results. Experiments were repeated at least twice. Scale bar, $100 \mu \mathrm{m}$. ${ }^{* *} \mathrm{P}<0.01 \mathrm{vs.} \mathrm{NG;}{ }^{\# \#} \mathrm{P}<0.01$ vs. unOC. unOC, uncarboxylated osteocalcin; BMSCs, bone marrow-derived mesenchymal stem cells; NG, normal group; NG + unOC, unOC-induced group; NG + ODI, osteogenic differentiation induction group; NG + ODI + unOC, unOC-induced osteogenic differentiation induction group.

and mRNA expression levels (Fig. 4G) as compared with those in the control $(\mathrm{NG}+\mathrm{NC})$ group. unOC $+\mathrm{NC}$ treatment significantly decreased the expression level of $\mathrm{C} / \mathrm{EBP} \alpha$ compared with the $\mathrm{NG}+\mathrm{NC}$ group and the SIRT1 siRNA group (Fig. 4C and G). There was no significant difference in $\mathrm{C} / \mathrm{EBP} \alpha$ expression between the unOC + SIRT1 siRNA treatment group and the SIRT1 siRNA group. The protein expression levels of SIRT1 markedly increased in the unOC $+\mathrm{NC}$ treatment group compared with those in the $\mathrm{NG}+\mathrm{NC}$ group (Fig. 4C and F). By contrast, the expression levels of SIRT1 were markedly decreased in the SIRT1 siRNA group compared with those in the $\mathrm{NG}+\mathrm{NC}$ group. There was no significant difference between the unOC + SIRT1 siRNA treatment group and the NG + SIRT1 siRNA group. Collectively, the data suggested that the regulation of SIRT1 by unOC in BMSCs inhibited adipogenic differentiation and, thus, promoted osteogenic differentiation.
unOC promotes osteogenic differentiation of BMSCs through PKA-AMPK-SIRT1

unOC can upregulate the expression levels of $p-P K A$, $p$-AMPK and SIRT1. As PKA and AMPK regulate SIRT1 in cell differentiation $(37,38)$, the PKA-AMPK pathway was examined to find if it was required for unOC to promote osteogenic differentiation in BMSCs. The PKA inhibitor, H89, was used to detect the signaling pathway through which unOC regulated the differentiation of mouse BMSCs. It was found that unOC treatment significantly increased the protein level of p-PKA, p-AMPK and SIRT1 in BMSCs compared with their expression in the NG group (Fig. 5A-D). In contrast, the increased expression levels were completely abolished and even reversed by H89, while the expression levels of PKA and AMPK remained the same, indicating that unOC positively regulated the PKA-AMPK-SIRT1 pathway by upregulating p-PKA and p-AMPK. Furthermore, simultaneous treatment 
A

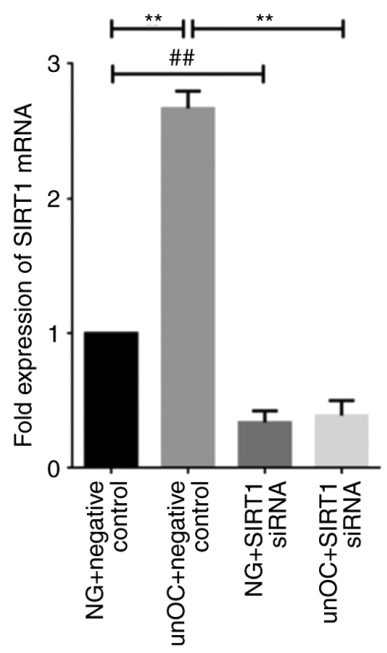

B

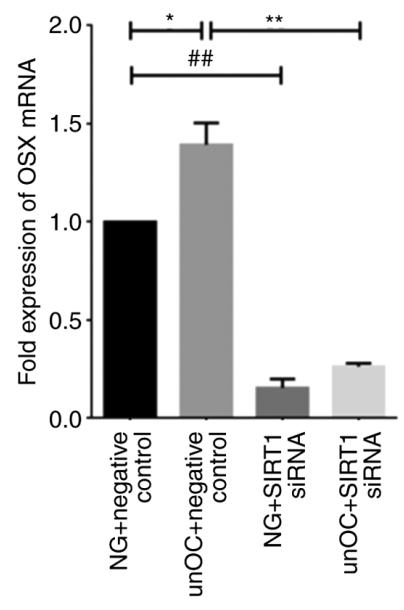

$\mathrm{D}$

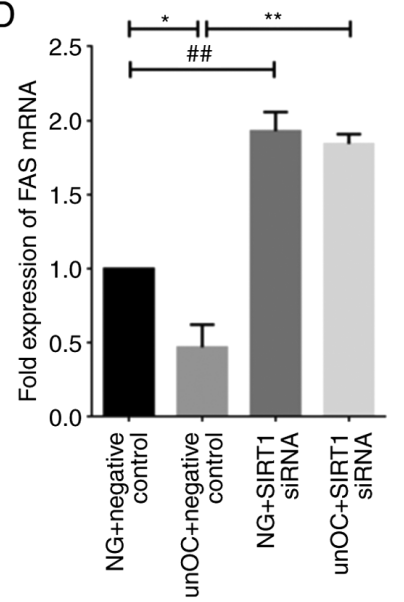

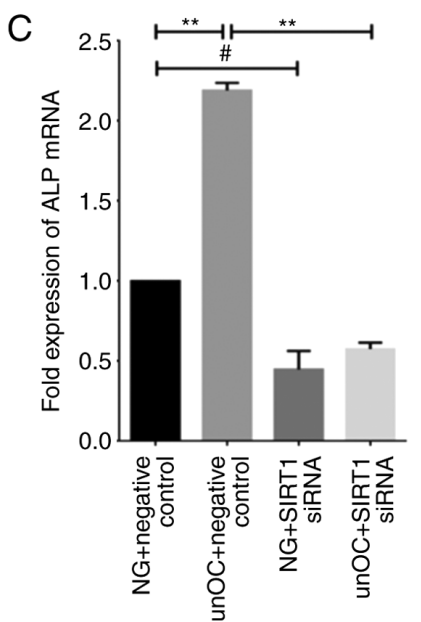

$\mathrm{E}$

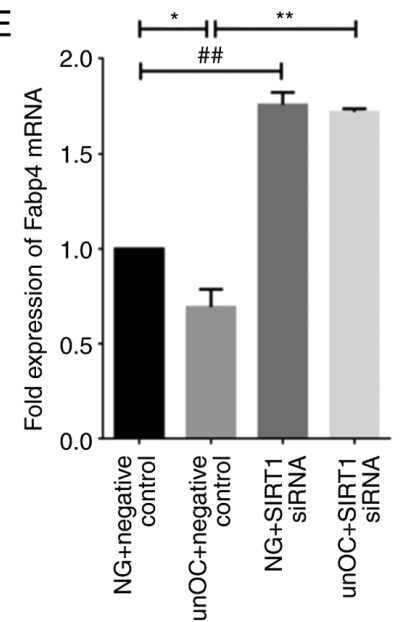

Figure 3. unOC promotes osteogenic differentiation and inhibits adipogenic differentiation of BMSCs through SIRT1. RT-qPCR analysis of total cellular RNA from four cell culture groups: NG + NC Group, unOC + NC group, SIRT1 siRNA group and unOC + SIRT1 siRNA treatment group. (A) mRNA expression levels of SIRT1 in the different groups. RT-qPCR was used to determine the mRNA expression levels of (B) OSX, (C) ALP, (D) FAS and (E) Fabp4. Experiments were repeated at least three times. ${ }^{*} \mathrm{P}<0.05,{ }^{* *} \mathrm{P}<0.01 \mathrm{vs}$. unOC $+\mathrm{NC} ;{ }^{\#} \mathrm{P}<0.05,{ }^{\# \#} \mathrm{P}<0.01$ vs. NG $+\mathrm{SIRT} 1$ siRNA. unOC, uncarboxylated osteocalcin; BMSCs, bone marrow-derived mesenchymal stem cells; SIRT1, sirtuin 1; RT-qPCR, reverse transcription-quantitative PCR; NG, normal group; NC, negative control; si-small interfering; FAS, fatty acid synthase; Fabp4, fatty acid-binding protein 4; Osx, osterix; ALP, alkaline phosphatase.

with $\mathrm{H} 89$ and unOC restored the expression of p-PKA, p-AMPK and SIRT1 (Fig. 5). Collectively, the data indicated that unOC functioned upstream of the PKA-AMPK-SIRT1 pathway, thereby promoting the expression levels of p-AMPK and SIRT1.

unOC regulates the differentiation of BMSCs through the PKA-AMPK-SIRT1 pathway. To study the unOC-regulated PKA signaling pathways involved in the differentiation of mouse BMSCs, the AMPK inhibitor, Dorsomorphin, was examined using western blot analysis. Compared with the NG group, the levels of p-AMPK, p-PKA and SIRT1 were significantly increased in the unOC group, but there was no obvious trend in total PKA (Fig. 6). This change also appeared in the comparison between the NG + Dorsomorphin group and the unOC + Dorsomorphin group (Fig. 6). However, in the NG + Dorsomorphin group compared with the NG group, or the unOC + Dorsomorphin group compared with the unOC group, there was no statistical difference between P-PKA and total PKA. This is related to Dorsomorphin only inhibiting AMPK, but also indicates that AMPK is a downstream regulator of
PKA (Fig. 6). After treating cells with Dorsomorphin, the phosphorylation of AMPK and SIRT1 in the NG + Dorsomorphin decreased compared with that in the NG group, but that of PKA did not change significantly (Fig. 6B-D). In addition, after adding Dorsomorphin and unOC to the BMSCs, both p-AMPK and SIRT1 expression levels were restored to similar levels of the NG group. These results indicated that unOC upregulated the expression of PKA, increased the phosphorylation level of the downstream target AMPK and promoted the expression of SIRT1. Through the aforementioned experiments, it was concluded that unOC promoted the osteogenic differentiation of mouse BMSCs through the PKA-AMPK-SIRT1 pathway.

\section{Discussion}

Previous studies have shown that the differentiation of BMSCs plays a noteworthy role in osteoporosis treatment as a therapeutic application (39-41). BMSCs can differentiate into osteoblasts, which can serve important functions in the synthesizing bone matrix (42). Osteoblasts, as the key cells for mediating bone formation, are embedded into the bone tissue 
A

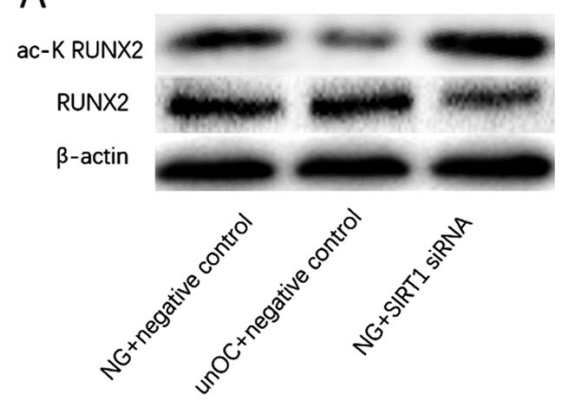

B

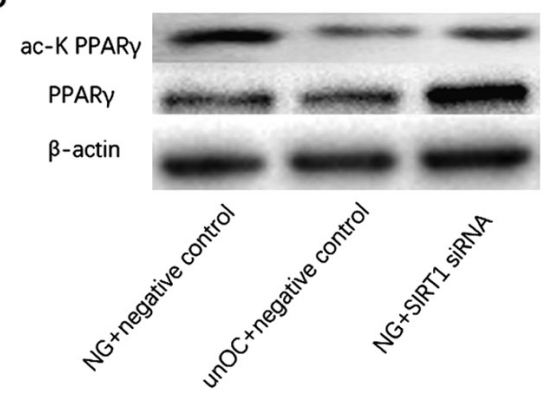

C

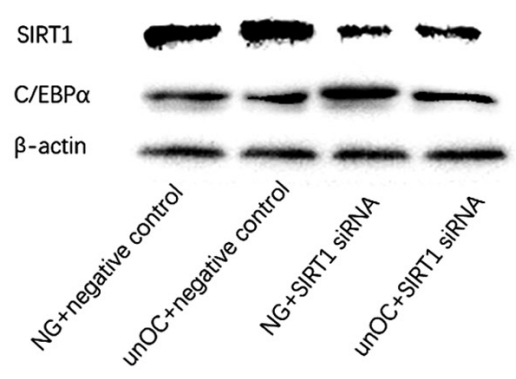

D

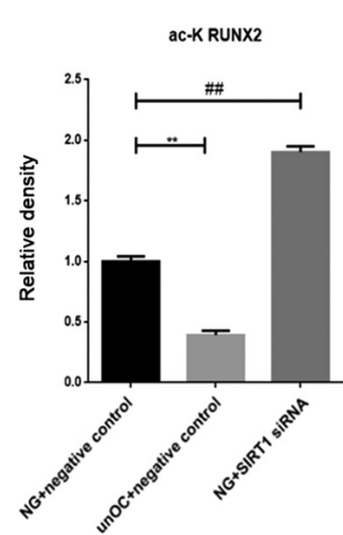

$\mathrm{E}$

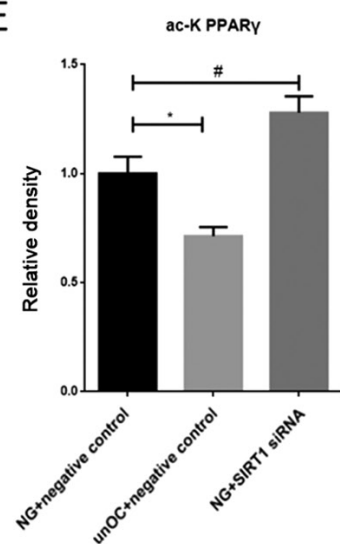

$\mathrm{F}$

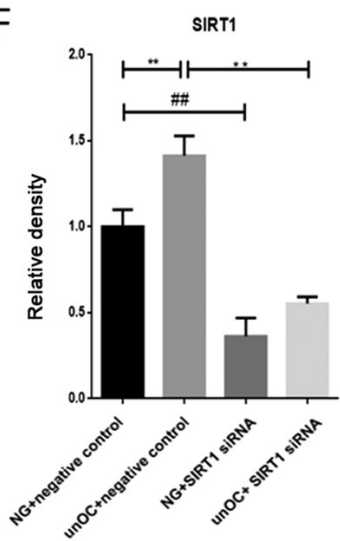

G

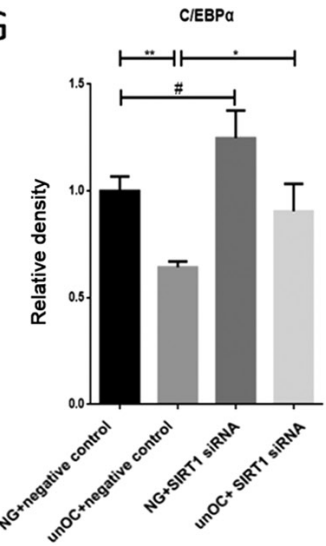

Figure 4. unOC regulates the differentiation of BMSCs through SIRT1 deacetylation of RUNX2 and PPAR $\gamma$. Western blot analysis of the total and acetylated (A) RUNX2 and (B) PPAR $\gamma$. (C) Western blot analysis of SIRT1 and C/EBPa protein expression levels in the cell lysates of the four treatment groups after transfection with the lentiviral vector or vector control. Ratios of acetylated protein:total protein of (D) RUNX2 and (E) PPAR $\gamma$. Gray value analysis of (F) SIRT1 and (G) C/EBP $\alpha$. Experiments were repeated at least three times. ${ }^{*} \mathrm{P}<0.05,{ }^{* *} \mathrm{P}<0.01$ vs. unOC $+\mathrm{NC}$; ${ }^{\#} \mathrm{P}<0.05$, ${ }^{\# \#} \mathrm{P}<0.01$ vs. NG + SIRT1 siRNA. unOC, uncarboxylated osteocalcin; BMSCs, bone marrow-derived mesenchymal stem cells; SIRT1, sirtuin 1; RUNX2, runt-related transcription factor 2; PPAR $\gamma$, peroxisome proliferator-activated receptor $\gamma$; C/EBPa, CCAAT-enhancer-binding protein $\alpha$; NG, normal group; NC, negative control; si-small interfering. $\mathrm{C} / \mathrm{EBP} \alpha, \mathrm{CCAAT}-$ enhancer-binding protein a.

after the mineralization process to eventually become bone cells and form are one of the most important components of the bone (43). Studies have shown that osteoporosis is related to the adipogenic differentiation and aging of BMSCs $(40,44)$. At the same time, promoting the osteogenic differentiation of BMSCs has predictable help in treating or reducing osteoporosis $(45,46)$. Although the regulation and shift of the cell differentiation of BMSCs to osteoblasts rather than adipocytes is needed for the treatment of osteoporosis, the molecular mechanism responsible for this regulation of BMSCs has not been defined (39). Our previous study showed that unOC can regulate the differentiation shift of BMSCs to osteoblasts (16), suggesting its role as a potential treatment candidate for osteoporosis. The current study provided insights into the underlying mechanisms by identifying the downstream unOC regulatory pathway and the critical factor, SIRT1.

SIRT1, a core member of the sirtuin family of proteins, is an $\mathrm{NAD}^{+}$-dependent deacetylase. The main function of SIRT1 is to deacetylate histones and non-histone proteins in an organism (47). It affects cell proliferation, differentiation, metabolism, autophagy (48), cancer (49), inflammation, diabetes (50), osteoporosis (51) and other diseases closely associated with the health and aging of the body (52). It also plays an important role in regulating the differentiation of BMSCs. BMSC-specific SIRT1-knockout mice display reduced cell proliferation and accelerated cell senescence (53).
In contrast, the overexpression of SIRT1 delays senescence in BMSCs, which extends the cell life span in vitro, and the cells do not lose the potential for osteogenic and adipogenic differentiation (53). These findings uncovered potential therapeutic applications of BMSCs in tissue engineering (54). SIRT1 also prevents senescence in human BMSCs (53), suggesting a regulatory role for SIRT1 in the proliferation and differentiation of MSCs in humans. The present study found that the expression of SIRT1 is positively regulated by unOC in BMSCs, suggesting that SIRT1 is likely to play a role in mediating the effect of unOC on BMSC differentiation.

The dynamic balance between bone formation and bone resorption is the basis of bone remodeling and homeostasis (55). In addition to regulating the differentiation of MSCs (56), SIRT1 is also involved in the regulation of bone metabolism in the body $(57,58)$. It maintains the normal bone remodeling process by regulating factors that are associated with bone metabolism, such as SOX9, PPAR $\gamma, \mathrm{NF}-\kappa \mathrm{B}$ and RUNX2. SIRT1 deacetylates SOX9 and PPAR $\gamma$, enhances SOX9 activity and reduces PPAR $\gamma$ activity, thereby regulating the differentiation of MSCs into chondrocytes and inhibiting their differentiation into adipocytes (22). SIRT1 inhibits $\mathrm{NF}-\kappa \mathrm{B}$ signaling to maintain normal skeletal remodeling (59).

SIRT1 is known to play a notable role in bone metabolism by promoting osteoblast differentiation, inhibiting osteoclast formation and reducing osteolysis $(57,59)$. First, SIRT1 
A
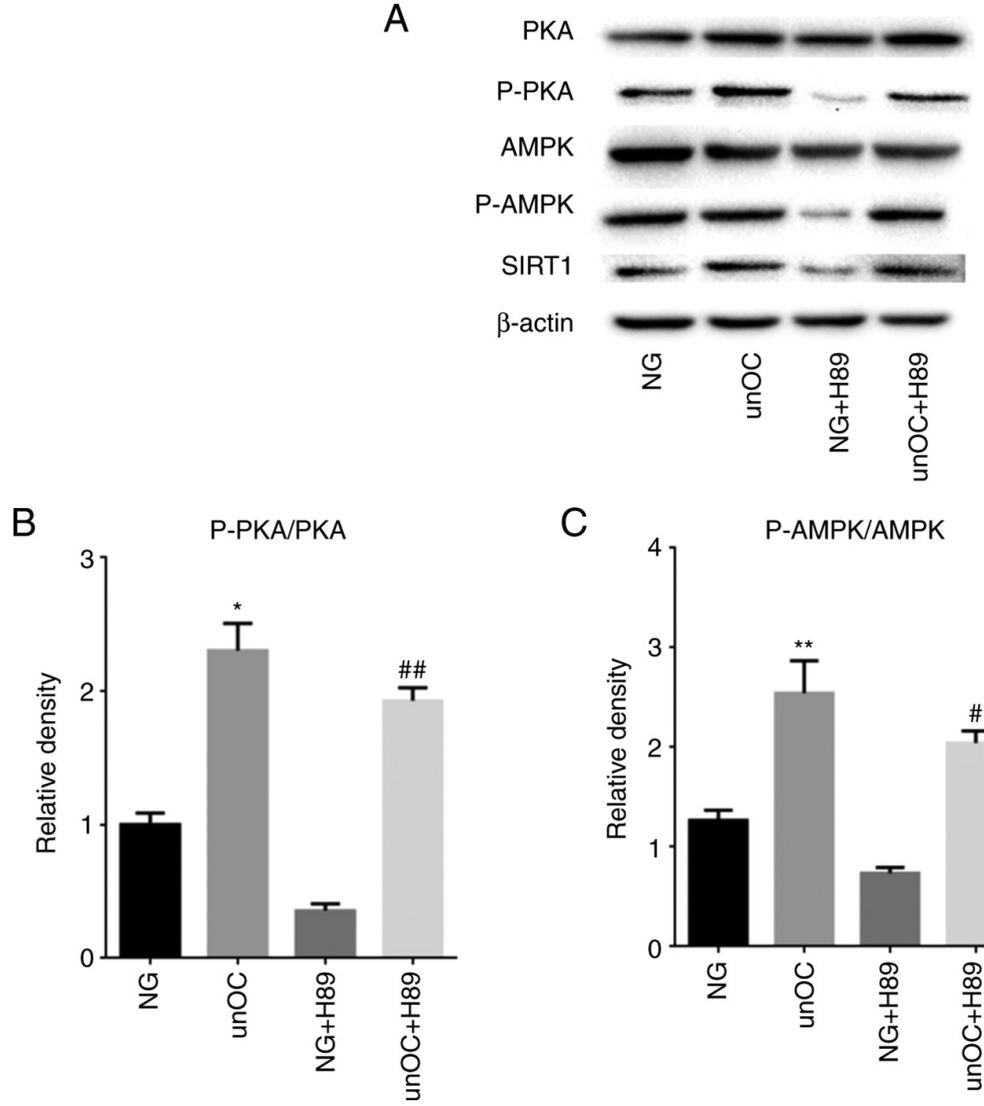

C

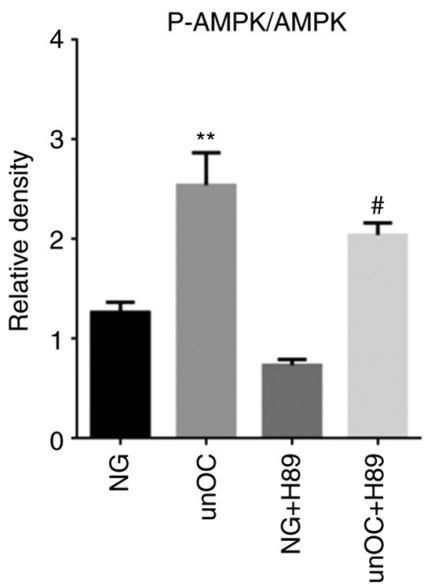

D

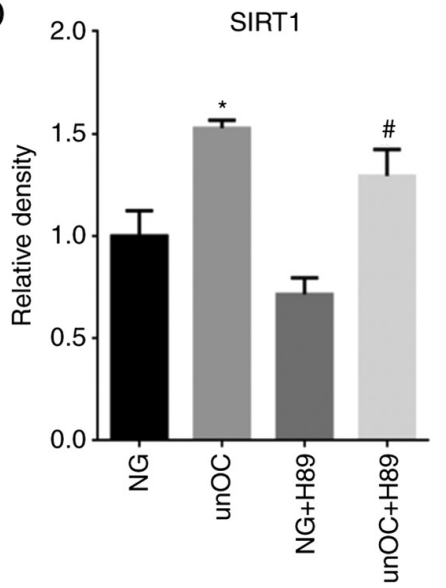

Figure 5. unOC upregulates the expression of p-PKA and p-AMPK and SIRT1. Cells were divided into the NG, unOC-treated, PKA inhibitor H89 and PKA inhibitor H89 + unOC groups. (A) Western blot analysis to detect the levels of total PKA, total AMPK, p-AMPK, p-PKA and SIRT1. p-protein was normalized with the corresponding total protein, and the ratio was calculated for (B) PKA and (C) AMPK. (D) Quantified SIRT1 protein levels. Experiments were repeated at least three times. ${ }^{*} \mathrm{P}<0.05,{ }^{* *} \mathrm{P}<0.01 \mathrm{vs}$. NG; ${ }^{\#} \mathrm{P}<0.05,{ }^{\#} \mathrm{P}<0.01 \mathrm{vs}$. NG $+\mathrm{H} 89$. unOC, uncarboxylated osteocalcin; BMSCs, bone marrow-derived mesenchymal stem cells; SIRT1, sirtuin 1; NG, normal group; p-phosphorylated; PKA, protein kinase A; AMPK, AMP-activated protein kinase.

promotes osteogenic differentiation and inhibits adipogenic differentiation in human dental pulp stem cells by regulating the Wnt/ $\beta$-catenin signaling pathway $(20,60)$. Second, SIRT1 is a positive regulator of the osteoblast transcription factor, RUNX2.RUNX2 is one of the key osteogenic cytokines $(61,62)$. RUNX2-deficient mice exhibit a complete absence of mature osteoblasts and obvious defects in bone mineralization (63). Zainabadi et al (21) found that SIRT1-deficient mice had lower expression levels of RUNX2 downstream targets, including osteopontin and OSX, and decreased osteogenic differentiation. In contrast, MSCs treated with SIRT1 agonists show decreased RUNX2 acetylation, increased expression levels of RUNX2 targets and enhanced osteoblast differentiation. Thirdly, SIRT1 inhibits the osteoclast process by regulating the $N F-\kappa B$ signaling pathway. $N F-\kappa B$ is a type of nuclear transcription factor associated with cellular immunity, apoptosis and differentiation. The activation of $N F-\kappa B$ promotes the receptor activator of nuclear factor $-\kappa B$ ligand-induced osteoclast formation (64). SIRT1 and NF- $\kappa$ B have a mutual inhibitory relationship. The SIRT1 activator, resveratrol, activates the expression of NF- $\mathrm{B}$ inhibitory protein $\alpha$. Furthermore, SIRT1 directly inhibits NF- $\kappa \mathrm{B}$ signaling by deacetylating the p65 subunit of the NF- $\kappa \mathrm{B}$ complex and inhibits its accumulation in the nucleus (65). Thus, the inhibition of NF- $\kappa \mathrm{B}$ signaling reduces the formation of osteoclasts and adipocytes and increases the number of osteoblasts, which further reduces bone resorption, increases bone formation, restores bone mass and corrects bone metabolism imbalance (51). In contrast, NF- $\kappa \mathrm{B}$ downregulates SIRT1 activity through decreased intracellular NAD ${ }^{+}$levels (66). Thus, both $\mathrm{NF}-\kappa \mathrm{B}$ and SIRT1 restrict each other and participate in the regulation of osteogenic differentiation and bone metabolism.

In summary, SIRT1 has potential for restoring bone metabolism and treating osteoporosis by regulating the osteogenic differentiation of MSCs. The findings of the present study are consistent with previous reports that SIRT1 deacetylates RUNX2 and PPAR $\gamma$ and regulates their activity (67). unOC treatment was also found to upregulate SIRT1 expression, which lead to increased deacetylation of RUNX2 and PPAR $\gamma$. According to a previous study, the activity of RUNX2 was enhanced after deacetylation whereas the activity of deacetylated PPAR $\gamma$ was reduced, thereby promoting the differentiation of BMSCs into osteoblasts and inhibiting their differentiation into adipocytes $(21,22)$.

unOC promotes BMSC differentiation and inhibits adipogenesis through SIRT1, which may serve as a novel target for osteoporosis treatment (68). Studies have shown that unOC has a wide range of biological functions. It is involved in vital life processes, such as differentiation, metabolism and cognition (69-73). unOC also plays an active role in the regulation of bone metabolism (74), cardiovascular disease (75) and melanoma (76). 
A

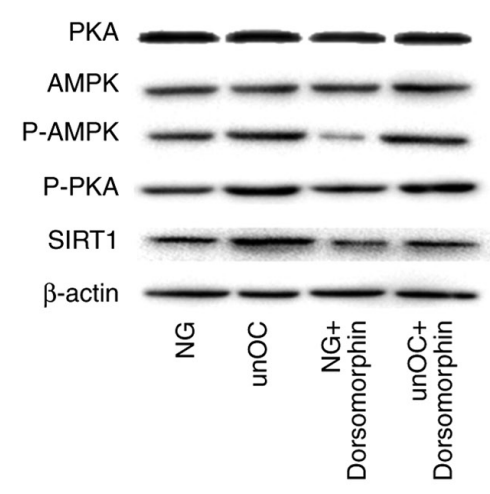

B

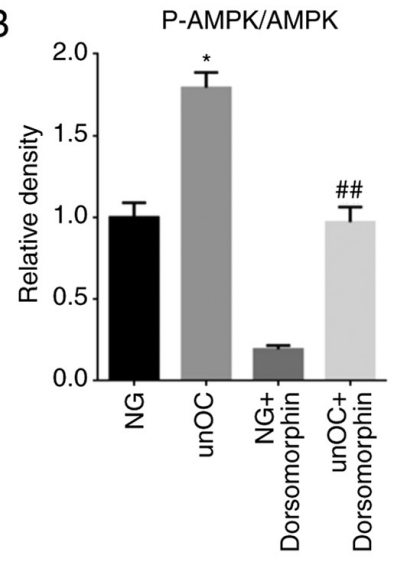

C

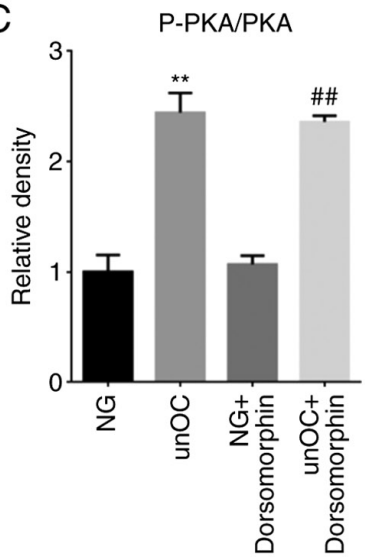

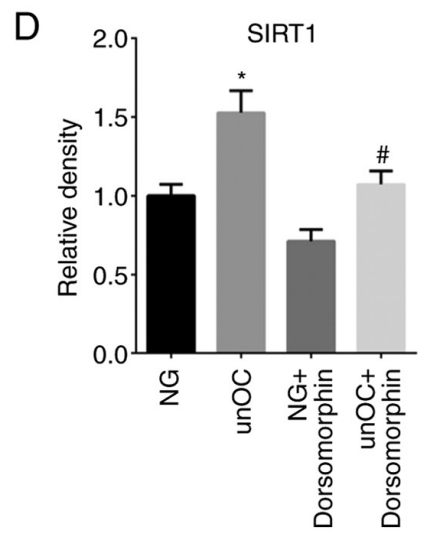

Figure 6. unOC regulates mesenchymal stem cell differentiation through the PKA-AMPK-SIRT1 axis. Cells were divided into: NG, unOC-Treated, AMPK inhibitor Dorsomorphin and Dorsomorphin and unOC groups. (A) Western blot analysis to detect total AMPK, total PKA, p-PKA, p-AMPK and SIRT1 protein expression levels after 2 days. P-protein was normalized to the corresponding total protein, and the ratio was calculated for (B) AMPK and (C) PKA. (D) Quantified SIRT1 protein levels. Experiments were repeated at least three times. ${ }^{*} \mathrm{P}<0.05,{ }^{* *} \mathrm{P}<0.01$ vs. NG; ${ }^{*} \mathrm{P}<0.05,{ }^{\# \#} \mathrm{P}<0.01$ vs. NG + Dorsomorphin. unOC, uncarboxylated osteocalcin; BMSCs, bone marrow-derived mesenchymal stem cells; SIRT1, sirtuin 1; NG, normal group; p-phosphorylated; PKA, protein kinase A; AMPK, AMP-activated protein kinase.

Multiple lines of evidence indicate that unOC is involved in BMSC differentiation. Studies have shown that mineral maturation and total hydroxyapatite content are reduced as a result of decreased levels of the osteocalcin gene in BMSCs (77-79). This suggests that osteocalcin can be induced by promoting bone differentiation (80) and is conducive to the recovery of bone metabolism (81). Our previous studies have shown that unOC stimulates the differentiation of pre-bone MC3T3-E1 cells (27) and BMSCs (16) into bone cells. The present study demonstrated that unOC promoted osteogenic differentiation and inhibited adipogenic differentiation in BMSCs via the PKA-AMPK-SIRT1 signaling pathway as the PKA inhibitor, H89, abolished the upregulation of SIRT1, p-PKA and AMPK via unOC. Moreover, treatment with Dorsomorphin, an AMPK inhibitor, reversed the effect of unOC on SIRT1 and AMPK, but not on PKA. These findings suggested that unOC functioned via the PKA-AMPK-SIRT1 pathway in regulating BMSC differentiation. However, Dorsomorphin is also an inhibitor to bone morphogenetic protein (BMP), which is known to be involved in adipogenesis $(82,83)$. Therefore, it is possible that BMP also plays a role in mediating the function of unOC on BMSC differentiation. Further studies are required to confirm this theory.

There are some limitations in the present study. First of all, the cells used in the present study were extracted from the femur of C57 mice, which are different from the BMSCs of humans $(84,85)$, Especially the osteoarthritis of patients with osteoarthritis will show higher levels of osteocalcin and type I collagen (86). In addition, used 3rd to 5th generations of BMSCs were used from 4-week-old mice, where it has been reported that the pathological characteristics of patients with osteoporosis are significantly different in the early, middle and late stages (87). Therefore, future research would need to involve the comparison of the treatment effects of unOC on osteoporosis at different pathological stages.

The present study provided several lines of evidence that SIRT1 was a key target of unOC-mediated regulation of BMSC differentiation into osteoblasts. Firstly, unOC directly shifted the differentiation potential via SIRT1. SIRT1 was required for unOC-mediated upregulation of pro-osteogenic differentiation factors, ALP and OSX, and unOC-induced downregulation of pro-adipogenic differentiation factors, FAS and Fabp4. Secondly, unOC shifted the differentiation potential of BMSCs via SIRT1 by inducing the deacetylation of the downstream targets, RUNX2 and PPAR $\gamma$. Finally, unOC upregulated SIRT1 expression through the PKA-AMPK pathway. Collectively, these data indicated that unOC has the potential to promote the differentiation of BMSCs into osteoblasts or tissue regeneration, suggesting its potential in clinical practice, especially in the treatment of osteoporosis. 


\section{Acknowledgements}

Not applicable.

\section{Funding}

The present study was supported by grants from The Knowledge Innovation Program of The Chinese Academy of Sciences (grant nos. KSCX2-EW-J-29 and Y129015EA2) and The College of Life Sciences, University of Chinese Academy of Sciences (grant no. KJRH2015-006).

\section{Availability of data and materials}

The datasets used and/or analyzed during the current study are available from the corresponding author on reasonable request.

\section{Authors' contributions}

LG designed and performed the majority of the investigation and performed data analysis. FZG and JHY provided assistance in designing animal experiments. LYM, JHY and FZG contributed to the interpretation of the data and analyses. All authors have read and approved the final manuscript. LG and FZG confirm the authenticity of all the raw data.

\section{Ethics approval and consent to participate}

The present study was approved by The Institutional Animal Care and Use Committee of The University of Chinese Academy of Sciences (Beijing, China).

\section{Patient consent for publication}

Not applicable.

\section{Competing interests}

The authors declare that they have no competing interests.

\section{References}

1. Peterson JA: Osteoporosis overview. Geriatr Nurs 22: 17-21, 2001.

2. Wang C, Meng H, Wang X, Zhao C, Peng J and Wang Y: Differentiation of bone marrow mesenchymal stem cells in osteoblasts and adipocytes and its role in treatment of osteoporosis. Med Sci Monit 22: 226-233, 2016.

3. Kiernan J, Davies JE and Stanford WL: Concise review: Musculoskeletal stem cells to treat age-related osteoporosis. Stem Cells Transl Med 6: 1930-1939, 2017.

4. Fu X, Liu G, Halim A, Ju Y, Luo Q and Song AG: Mesenchyma stem cell migration and tissue repair. Cells 8: 784, 2019.

5. Mo J, Yang R, Li F, He B, Zhang X, Zhao Y, Shen Z and Chen P: Geraniin promotes osteogenic differentiation of bone marrow mesenchymal stem cells (BMSCs) via activating $\beta$-catenin: A comparative study between BMSCs from normal and osteoporotic rats. J Nat Med 73: 262-272, 2019.

6. Luo Y, Zhang Y, Miao G, Zhang Y, Liu Y and Huang Y: Runx1 regulates osteogenic differentiation of BMSCs by inhibiting adipogenesis through Wnt/ $\beta$-catenin pathway. Arch Oral Biol 97: 176-184, 2019

7. Ganguly P, El-Jawhari JJ, Giannoudis PV, Burska AN, Ponchel F and Jones EA: Age-related changes in bone marrow mesenchymal stromal cells: A potential impact on osteoporosis and osteoarthritis development. Cell Transplant 26: 1520-1529, 2017.
8. Baker N, Boyette LB and Tuan RS: Characterization of bone marrow-derived mesenchymal stem cells in aging. Bone 70: 37-47, 2015.

9. Chen Q, Shou P, Zheng C, Jiang M, Cao G, Yang Q, Cao J Xie N, Velletri T, Zhang X, et al: Fate decision of mesenchymal stem cells: Adipocytes or osteoblasts? Cell Death Differ 23: 1128-1139, 2016.

10. Ducy P: The role of osteocalcin in the endocrine cross-talk between bone remodelling and energy metabolism. Diabetologia 54: 1291-1297, 2011.

11. Zoch ML, Clemens TL and Riddle RC: New insights into the biology of osteocalcin. Bone 82: 42-49, 2016.

12. Iwamoto J, Takeda T and Sato Y: Effects of vitamin K2 on osteoporosis. Curr Pharm Des 10: 2557-2576, 2004.

13. Berezovska O, Yildirim G, Budell WC, Yagerman S, Pidhayny $\mathrm{B}$, Bastien C, van der Meulen MCH and Dowd TL: Osteocalcin affects bone mineral and mechanical properties in female mice. Bone 128: 115031, 2019.

14. Neve A, Corrado A and Cantatore FP: Osteocalcin: Skeletal and extra-skeletal effects. J Cell Physiol 228: 1149-1153, 2013.

15. Le VD and Marcil V: Osteocalcin and glucose metabolism: Assessment of human studies. Med Sci (Paris) 33: 417-422, 2017.

16. Liu Z and Yang J: Uncarboxylated osteocalcin promotes osteogenic differentiation of mouse bone marrow-derived mesenchymal stem cells by activating the Erk-Smad/ $\beta$-catenin signalling pathways. Cell Biochem Funct 38: 87-96, 2020.

17. Choi SM, Lee KM, Ryu SB, Park YJ, Hwang YG, Baek D, Choi Y, Park KH, Park KD and Lee JW: Enhanced articular cartilage regeneration with SIRT1-activated MSCs using gelatin-based hydrogel. Cell Death Dis 9: 866, 2018.

18. Chen Y, Zhou F, Liu H, Li J, Che H, Shen J and Luo E: SIRT1, a promising regulator of bone homeostasis. Life Sci 269: 119041, 2021.

19. Simic P, Zainabadi K, Bell E, Sykes DB, Saez B, Lotinun S, Baron R, Scadden D, Schipani E and Guarente L: SIRT1 regulates differentiation of mesenchymal stem cells by deacetylating $\beta$-catenin. EMBO Mol Med 5: 430-440, 2013.

20. Zhou Y, Song T, Peng J, Zhou Z, Wei H, Zhou R, Jiang S and Peng J: SIRT1 suppresses adipogenesis by activating $\mathrm{Wnt} / \beta$-catenin signaling in vivo and in vitro. Oncotarget 7 : 77707-77720, 2016.

21. Zainabadi K, Liu CJ and Guarente L: SIRT1 is a positive regulator of the master osteoblast transcription factor, RUNX2. PLoS One 12: e0178520, 2017.

22. Qu P, Wang L, Min Y, McKennett L, Keller JR and Lin PC: Vavl regulates mesenchymal stem cell differentiation decision between adipocyte and chondrocyte via Sirt1. Stem Cells 34: 1934-1946, 2016

23. Ha J, Guan KL and Kim J: AMPK and autophagy in glucose/glycogen metabolism. Mol Aspects Med 46: 46-62,2015.

24. Wang Y, Chen G, Yan J, Chen X, He F, Zhu C, Zhang J, Lin J, Pan G, Yu J, et al: Upregulation of SIRT1 by kartogenin enhances antioxidant functions and promotes osteogenesis in human mesenchymal stem cells. Oxid Med Cell Longev 2018: $1368142,2018$.

25. Chen H, Liu X, Chen H, Cao J, Zhang L, Hu X and Wang J: Role of SIRT1 and AMPK in mesenchymal stem cells differentiation. Ageing Res Rev 13: 55-64, 2014.

26. Shelly M, Cancedda L, Heilshorn S, Sumbre G and Poo MM: LKB1/STRAD promotes axon initiation during neuronal polarization. Cell 129: 565-577, 2007.

27. Liu J and Yang J: Uncarboxylated osteocalcin inhibits high glucose-induced ROS production and stimulates osteoblastic differentiation by preventing the activation of PI3K/Akt in MC3T3-E1 cells. Int J Mol Med 37: 173-181, 2016.

28. Kim JH, Park S, Kim HW and Jang JH: Recombinant expression of mouse osteocalcin protein in Escherichia coli. Biotechnol Lett 29: 1631-1635, 2007.

29. Cai Y, Liu T, Fang F, Xiong C and Shen S: Comparisons of mouse mesenchymal stem cells in primary adherent culture of compact bone fragments and whole bone marrow. Stem Cells Int 2015: 708906, 2015.

30. Liu G, Bi Y, Shen B, Yang H, Zhang Y, Wang X, Liu H, Lu Y, Liao J, Chen X and Chu Y: SIRT1 limits the function and fate of myeloid-derived suppressor cells in tumors by orchestrating HIF-1 $\alpha$-dependent glycolysis. Cancer Res 74: 727-737, 2014.

31. Amini E, Nassireslami E, Payandemehr B, Khodagholi F, Foolad F, Khalaj S, Hamedani MP, Azimi L and Sharifzadeh M: Paradoxical role of PKA inhibitor on amyloid $\beta$-induced memory deficit. Physiol Behav 149: 76-85, 2015. 
32. Liu X, Chhipa RR, Nakano I and Dasgupta B: The AMPK inhibitor compound $\mathrm{C}$ is a potent AMPK-independent antiglioma agent. Mol Cancer Ther 13: 596-605, 2014.

33. Hasegawa T: Ultrastructure and biological function of matrix vesicles in bone mineralization. Histochem Cell Biol 149: 289-304, 2018

34. Ishikane S, Ikushima E, Igawa K, Tomooka $\mathrm{K}$ and Takahashi-Yanaga F: Differentiation-inducing factor-1 potentiates adipogenic differentiation and attenuates the osteogenic differentiation of bone marrow-derived mesenchymal stem cells. Biochim Biophys Acta Mol Cell Res 1868: 118909, 2021.

35. Li D, Zhang R, Zhu W, Xue Y, Zhang Y, Huang Q, Liu M and Liu Y: S100A16 inhibits osteogenesis but stimulates adipogenesis. Mol Biol Rep 40: 3465-3473, 2013.

36. Picard F, Kurtev M, Chung N, Topark-Ngarm A, Senawong T, Machado De Oliveira R, Leid M, McBurney MW and Guarente L: Sirt1 promotes fat mobilization in white adipocytes by repressing PPAR-gamma. Nature 429: 771-776, 2004.

37. Huang Y, Zhu X, Chen K, Lang H, Zhang Y, Hou P, Ran L, Zhou M, Zheng J, Yi L, et al: Resveratrol prevents sarcopenic obesity by reversing mitochondrial dysfunction and oxidative stress via the PKA/LKB1/AMPK pathway. Aging 11: 2217-2240, 2019.

38. Chen Y, Zhang LS, Ren JL, Zhang YR, Wu N, Jia MZ, Yu YR, Ning ZP, Tang CS and Qi YF: Intermedin ${ }_{1-53}$ attenuates aging-associated vascular calcification in rats by upregulating sirtuin 1. Aging 12: 5651-5674, 2020.

39. Hu L, Yin C, Zhao F, Ali A, Ma J and Qian A: Mesenchymal stem cells: Cell fate decision to osteoblast or adipocyte and application in osteoporosis treatment. Int J Mol Sci 19: 360, 2018.

40. Qadir A, Liang S, Wu Z, Chen Z, Hu L and Qian A: Senile osteoporosis: The involvement of differentiation and senescence of bone marrow stromal cells. Int J Mol Sci 21: 349, 2020.

41. Yang X, Yang J, Lei P and Wen T: LncRNA MALAT1 shuttled by bone marrow-derived mesenchymal stem cells-secreted exosomes alleviates osteoporosis through mediating microRNA-34c/SATB2 axis. Aging 11: 8777-8791, 2019.

42. Blair HC, Larrouture QC, Li Y, Lin H, Beer-Stoltz D, Liu L, Tuan RS, Robinson LJ, Schlesinger PH and Nelson DJ: Osteoblast differentiation and bone matrix formation in vivo and in vitro. Tissue Eng Part B Rev 23: 268-280, 2017.

43. Florencio-Silva R, Sasso GR, Sasso-Cerri E, Simões MJ and Cerri PS: Biology of bone tissue: Structure, function, and factors that influence bone cells. Biomed Res Int 2015: 421746, 2015.

44. Li JY, Wei X, Sun Q, Zhao XQ, Zheng CY, Bai CX, Du J, Zhang Z, Zhu LG and Jia YS: MicroRNA-449b-5p promotes the progression of osteoporosis by inhibiting osteogenic differentiation of BMSCs via targeting Satb2. Eur Rev Med Pharmacol Sci 23: 6394-6403, 2019.

45. Li M, Xie Z, Li J, Lin J, Zheng G, Liu W, Tang S, Cen S, Ye G, $\mathrm{Li} \mathrm{Z}$, et al: GAS5 protects against osteoporosis by targeting UPF1/SMAD7 axis in osteoblast differentiation. Elife 9: e59079, 2020

46. Zhou J, Nie H, Liu P, Wang Z, Yao B and Yang L: Down-regulation of miR-339 promotes differentiation of BMSCs and alleviates osteoporosis by targeting DLX5. Eur Rev Med Pharmacol Sci 23: 29-36, 2019.

47. Ding RB, Bao J and Deng CX: Emerging roles of SIRT1 in fatty liver diseases. Int J Biol Sci 13: 852-867, 2017.

48. Imperatore F, Maurizio J, Vargas Aguilar S, Busch CJ, Favret J, Kowenz-Leutz E, Cathou W, Gentek R, Perrin P, Leutz A, et al: SIRT1 regulates macrophage self-renewal. EMBO J 36 : 2353-2372, 2017.

49. Mu N, Lei Y, Wang Y, Wang Y, Duan Q, Ma G, Liu X and Su L: Inhibition of SIRT1/2 upregulates HSPA5 acetylation and induces pro-survival autophagy via ATF4-DDIT4-mTORC1 axis in human lung cancer cells. Apoptosis 24: 798-811, 2019.

50. Strycharz J, Rygielska Z, Swiderska E, Drzewoski J, Szemraj J, Szmigiero L and Sliwinska A: SIRT1 as a therapeutic target in diabetic complications. Curr Med Chem 25: 1002-1035, 2018.

51. Wang X, Chen L and Peng W: Protective effects of resveratrol on osteoporosis via activation of the SIRT1-NF- $\kappa \mathrm{B}$ signaling pathway in rats. Exp Ther Med 14: 5032-5038, 2017.

52. Chang HC and Guarente L: SIRT1 and other sirtuins in metabolism. Trends Endocrinol Metab 25: 138-145, 2014.

53. Yuan HF, Zhai C, Yan XL, Zhao DD, Wang JX, Zeng Q, Chen L, Nan X, He LJ, Li ST, et al: SIRT1 is required for long-term growth of human mesenchymal stem cells. J Mol Med (Berl) 90: 389-400, 2012
54. Han X, Liu L, Wang F, Zhao X, Zhao D, Dai X and Li Y: Reconstruction of tissue-engineered bone with bone marrow mesenchymal stem cells and partially deproteinized bone in vitro. Cell Biol Int 36: 1049-1053, 2012.

55. Chang Y, Yu D, Chu W, Liu Z, Li H and Zhai Z: LncRNA expression profiles and the negative regulation of lncRNANOMMUT037835.2 in osteoclastogenesis. Bone 130: 115072, 2020.

56. Song J, Li J, Yang F, Ning G, Zhen L, Wu L, Zheng Y, Zhang Q, Lin D, Xie C and Peng L: Nicotinamide mononucleotide promotes osteogenesis and reduces adipogenesis by regulating mesenchymal stromal cells via the SIRT1 pathway in aged bone marrow. Cell Death Dis 10: 336, 2019.

57. Wang H, Hu Z, Wu J, Mei Y, Zhang Q, Zhang H, Miao D and Sun W: Sirt1 promotes osteogenic differentiation and increases alveolar bone mass via Bmil activation in mice. J Bone Miner Res 34: 1169-1181, 2019.

58. Domazetovic V, Marcucci G, Pierucci F, Bruno G, Di Cesare Mannelli L, Ghelardini C, Brandi ML, Iantomasi T, Meacci E and Vincenzini MT: Blueberry juice protects osteocytes and bone precursor cells against oxidative stress partly through SIRT1. FEBS Open Bio 9: 1082-1096, 2019.

59. Edwards JR, Perrien DS, Fleming N, Nyman JS, Ono K, Connelly L, Moore MM, Lwin ST, Yull FE, Mundy GR and Elefteriou F: Silent information regulator (Sir)T1 inhibits NF- $\kappa B$ signaling to maintain normal skeletal remodeling. J Bone Miner Res 28: 960-969, 2013.

60. Feng G, Zheng K, Song D, Xu K, Huang D, Zhang Y, Cao P, Shen S, Zhang J, Feng X and Zhang D: SIRT1 was involved in TNF- $\alpha$-promoted osteogenic differentiation of human DPSCs through Wnt/ $\beta$-catenin signal. In Vitro Cell Dev Biol Anim 52: 1001-1011, 2016

61. Constanze B, Popper B, Aggarwal BB and Shakibaei M: Evidence that TNF- $\beta$ suppresses osteoblast differentiation of mesenchymal stem cells and resveratrol reverses it through modulation of NF- $\kappa$ B, Sirt1 and Runx2. Cell Tissue Res 381: 83-98, 2020.

62. Hong W, Wei Z, Qiu Z, Li Z, Fu C, Ye Z and Xu X: Atorvastatin promotes bone formation in aged apoE(-/-) mice through the Sirt1-Runx2 axis. J Orthop Surg Res 15: 303, 2020.

63. Komori T, Yagi H, Nomura S, Yamaguchi A, Sasaki K, Deguchi K, Shimizu Y, Bronson RT, Gao YH, Inada M, et al: Targeted disruption of Cbfal results in a complete lack of bone formation owing to maturational arrest of osteoblasts. Cell 89: 755-764, 1997.

64. Lv ZT, Liang S, Chen K, Zhang JM, Cheng P, Guo JC, Yang Q, Zhou $\mathrm{CH}$, Liao $\mathrm{H}$ and Chen AM: FNDC4 inhibits RANKL-induced osteoclast formation by suppressing NF- $\kappa \mathrm{B}$ Activation and CXCL10 expression. Biomed Res Int 2018: 3936257, 2018

65. Kauppinen A, Suuronen T, Ojala J, Kaarniranta K and Salminen A: Antagonistic crosstalk between NF- $\kappa$ B and SIRT1 in the regulation of inflammation and metabolic disorders. Cell Signal 25: 1939-1948, 2013.

66. Zhou H, Shang L, Li X, Zhang X, Gao G, Guo C, Chen B, Liu Q, Gong Y and Shao C: Resveratrol augments the canonical Wnt signaling pathway in promoting osteoblastic differentiation of multipotent mesenchymal cells. Ex Cell Res 315: 2953-2962, 2009.

67. Shakibaei M, Shayan P, Busch F, Aldinger C, Buhrmann C, Lueders $\mathrm{C}$ and Mobasheri A: Resveratrol mediated modulation of Sirt-1/Runx2 promotes osteogenic differentiation of mesenchymal stem cells: Potential role of Runx2 deacetylation. PLoS One 7: e35712, 2012.

68. Zainabadi K: Drugs targeting SIRT1, a new generation of therapeutics for osteoporosis and other bone related disorders? Pharmacol Resh 143: 97-105, 2019.

69. Lieben L, Callewaert F and Bouillon R: Bone and metabolism: A complex crosstalk. Horm Res 71 (Suppl 1): S134-S138, 2009.

70. Confavreux CB: Bone: From a reservoir of minerals to a regulator of energy metabolism. Kidney Int Suppl 79: S14-S19, 2011.

71. De Toni L, De Filippis V, Tescari S, Ferigo M, Ferlin A, Scattolini V, Avogaro A, Vettor R and Foresta C: Uncarboxylated osteocalcin stimulates 25 -hydroxy vitamin $\mathrm{D}$ production in Leydig cell line through a GPRC6a-dependent pathway. Endocrinology 155: 4266-4274, 2014.

72. Gao J, Bai T, Ren L, Ding Y, Zhong X, Wang H, Guo Y, Li J, Liu Y and Zhang Y: The PLC/PKC/Ras/MEK/Kv channel pathway is involved in uncarboxylated osteocalcin-regulated insulin secretion in rats. Peptides 86: 72-79, 2016. 
73. Guedes JAC, Esteves JV, Morais MR, Zorn TM and Furuya DT: Osteocalcin improves insulin resistance and inflammation in obese mice: Participation of white adipose tissue and bone. Bone 115: 68-82, 2018.

74. Miyamoto T, Oguma Y, Sato Y, Kobayashi T, Ito E, Tani M, Miyamoto K, Nishiwaki Y, Ishida H, Otani T, et al: Elevated creatine kinase and lactic acid dehydrogenase and decreased osteocalcin and uncarboxylated osteocalcin are associated with bone stress injuries in young female athletes. Sci Rep 8: 18019, 2018.

75. Kim KM, Lim S, Moon JH, Jin H, Jung KY, Shin CS, Park KS Jang $\mathrm{HC}$ and Choi SH: Lower uncarboxylated osteocalcin and higher sclerostin levels are significantly associated with coronary artery disease. Bone 83: 178-183, 2016.

76. Hayashi Y, Kawakubo-Yasukochi T, Mizokami A, Hazekawa M, Yakura T, Naito M, Takeuchi H, Nakamura S and Hirata $M$ Uncarboxylated osteocalcin induces antitumor immunity against mouse melanoma cell growth. J Cancer 8: 2478-2486, 2017.

77. Tsao YT, Huang YJ, Wu HH, Liu YA, Liu YS and Lee OK: Osteocalcin mediates biomineralization during osteogenic maturation in human mesenchymal stromal cells. Int J Mol Sci 18: 159, 2017.

78. Lee YC, Chan YH, Hsieh SC, Lew WZ and Feng SW: Comparing the osteogenic potentials and bone regeneration capacities of bone marrow and dental pulp mesenchymal stem cells in a rabbit calvarial bone defect model. Int J Mol Sci 20: 5015, 2019.

79. Zhang J, Zhang W, Dai J, Wang X and Shen SG: Overexpression of Dlx2 enhances osteogenic differentiation of BMSCs and MC3T3-E1 cells via direct upregulation of Osteocalcin and Alp. Int J Oral Sci 11: 12, 2019.

80. Fratzl-Zelman N, Glantschnig H, Rumpler M, Nader A, Ellinger A and Varga F: The expression of matrix metalloproteinase-13 and osteocalcin in mouse osteoblasts is related to osteoblastic differentiation and is modulated by 1,25-dihydroxyvitamin D3 and thyroid hormones. Cell Biol Int 27: 459-468, 2003.
81. Roach HI: Why does bone matrix contain non-collagenous proteins? The possible roles of osteocalcin, osteonectin, osteopontin and bone sialoprotein in bone mineralisation and resorption. Cell Biol Int 18: 617-628, 1994.

82. Chung JE, Park JH, Yun JW, Kang YH, Park BW, Hwang SC, Cho YC, Sung IY, Woo DK and Byun JH: Cultured human periosteum-derived cells can differentiate into osteoblasts in a perioxisome proliferator-activated receptor gamma-mediated fashion via bone morphogenetic protein signaling. Int J Med Sci 13: 806-818, 2016.

83. Yu PB, Hong CC, Sachidanandan C, Babitt JL, Deng DY, Hoyng SA, Lin HY, Bloch KD and Peterson RT: Dorsomorphin inhibits BMP signals required for embryogenesis and iron metabolism. Nat Chem Biol 4: 33-41, 2008.

84. Ingersoll MA, Spanbroek R, Lottaz C, Gautier EL, Frankenberger M, Hoffmann R, Lang R, Haniffa M, Collin M, Tacke F, et al: Comparison of gene expression profiles between human and mouse monocyte subsets. Blood 115: e10-e19, 2010.

85. Uder C, Brückner S, Winkler S, Tautenhahn HM and Christ B: Mammalian MSC from selected species: Features and applications. Cytometry A 93: 32-49, 2018.

86. Couchourel D, Aubry I, Delalandre A, Lavigne M, Martel-Pelletier J, Pelletier JP and Lajeunesse D: Altered mineralization of human osteoarthritic osteoblasts is attributable to abnormal type I collagen production. Arthritis Rheum 60: 1438-1450, 2009.

87. Glaser DL and Kaplan FS: Osteoporosis. Definition and clinical presentation. Spine (Phila Pa 1976) 22 (Suppl 24): 12S-16S, 1997.

This work is licensed under a Creative Commons Attribution-NonCommercial-NoDerivatives 4.0 International (CC BY-NC-ND 4.0) License. 